EKSAKTA Vol. 12 No. $1,44-48$

\title{
Parameter Estimation in Probit Model for Multivariate Multinomial Response Using SMLE
}

\author{
Jaka Nugraha \\ Jurusan Statistika FMIPA-UII Yogyakarta \\ Email :jnugraha@fmipa.uii.ac.id
}

\begin{abstract}
In the research field of transportation, market research and politics, often involving the response of the multinomial multivariate observations. In this paper, we discused a modeling of multivariate multinomial responses using probit model. The estimated parameters were calculated using Maximum Likelihood Estimations (MLE) based on the GHK simulation. method known as Simulated Maximum Likelihood Estimations (SMLE).

Likelihood function on the Probit model contains probability values that must be resolved by simulation. By using the GHK simulation algorithm, the estimator equation has been obtained for the parameters in the model Probit
\end{abstract}

Keywords : Probit Model, Newton-Raphson Iteration, GHK simulator, MLE, simulated log-likelihood 